\title{
KOUROUMA: A FORJA DE UM FRANCÊS AFRICANIZADO DIANTE DE UM SISTEMA LITERÁRIO MUNDIAL
}

KOUROUMA: THE FORGE OF AN AFRICANIZED FRENCH BEFORE A WORLD LITERARY SYSTEM

Providence Bampoky 
Resumo: Partindo do argumento de Moretti (2000) de que o romance moderno desponta nas culturas periféricas não como desenvolvimento autônomo, mas como uma conciliação entre influência formal estrangeira e conteúdos locais, busco pensar, neste artigo, como Kourouma manipula a língua do colonizador para expressar nela sentimentos e realidades imaginadas na sua língua materna - o malinké ${ }^{1}$ e como ocorre dentro do sistema literário mundial esta luta pelo reconhecimento.

Palavras-chave: Literatura marfinense, francês africanizado, sistema literário mundial.

\footnotetext{
${ }^{1} \mathrm{O}$ termo designa o indivíduo que pertence ao grupo étnico malinké, mas também designa a língua. Tradicionalmente, agricultores, artesãs e de religião muçulmana altamente influenciados pelas crenças animistas, os malinkés estão agrupados na Guiné, no Mali, na Costa do Marfim, no Senegal, na Gâmbia, na Serra Leoa, no Burkina Faso, na Guiné-Bissau, na Libéria e no Gana.
} 
Abstract: Taking Franco Moretti's (2000) argument as a starting point, which argues how the modern novel emerges in peripheral cultures not as an autonomous development, but as a problematic and unstable reconciliation between a formal foreign influence and the local contentes. I seek to think in this article how Kourouma manipulates the language of the colonizer (French) to express in it the feelings and realities imagined in his mother tongue (Malinké).and how the struggle for recognition takes place in the world literary system.

Keywords Ivorian literature, Africanized French, world literary system. 
A literatura africana de expressão francesa nasceu e se consolidou fora do continente negro, especificamente na França, onde residiu a maioria dos seus escritores, desde a década dos anos 1930, quando começou a aflorar a Negritude, inscrita como um dos movimentos da história literária que reuniu o mundo negro africano e, mais tarde, gerações de escritores pós-coloniais. As obras produzidas nesse período expressam a luta, a revolta no sentido do compromisso literário. Os autores denunciam o modo como os poderes instituídos passaram a se apresentar após a independência - a aparência de uma democracia corrupta. Eles apresentam nas suas narrativas a vida de personagens em busca de um novo mundo para o povo acostumado com a miséria. Portando, os intelectuais africanos envolvidos com os problemas de seus países tentam desafiar a imagem da África que lhes é imposta de forma violenta e empreendem, por si mesmos, pesquisas sobre a África e os seus povos. Dessa forma, a literatura também se torna um veículo de informação etnográfica e sociológica, em busca por uma identidade nacional. É nesse viés que se inscreve a produção literária do marfinense Ahmadou Kourouma (1927-2003), conhecido como romancista da segunda geração da história literária de expressão francesa. 0 romancista, na maioria das suas obras, entrega-nos um vasto panorama histórico que 
retraça simultaneamente os meandros do universo colonial e pós-colonial.

De origem malinké de uma família griot originária do norte da Costa de marfim, Kourouma exila-se mais de vinte anos na França, logo após a publicação do seu primeiro romance, Les soleils des indépendances (1968), que tem aquecido debates nos circuitos literários pela originalidade da expressão e pela inovação no vocabulário africano transposto em francês. 0 romance retrata o protagonismo de um príncipe malinké Fama, reduzido à miséria e à esterilidade após a independência de um dos novos Estados africanos (Costa de Marfim). Com a publicação deste romance, Kourouma foi considerado um dos escritores mais importantes da literatura subsaariana. Sem dúvida, a obra inaugura uma nova forma de pensar o romance africano. Ele será seguido de Monnè, outrage et défis (1990), também elevado ao nível de "clássico" da literatura africana. Além de uma peça teatral, Le diseur de vérité (2004) e alguns livros infantis, Kourouma publica En attendant le vote des bêtes sauvages (1998) e, por último, Allah n'est pas obligé (2000), que lhe valeu o cobiçado prêmio literário Renaudot por expor os sofrimentos atrozes de que foram vítimas milhares de crianças combatentes durante as guerras civis africanas, especificamente, na Serra Leoa e na Libéria nos anos de 1990. 


\section{A forja de um francês africanizado}

Monnè, outrage et défis (1990) coloca em cena a épica trágica e derrisória de um povo entregue à colonização, sua sátira de Estado africano moderno entregue aos seus demônios (Kourouma, 1990). A saga do romance centraliza-se, exclusivamente, na Costa de Marfim e nos tumultos do seu passado colonial, mas também esboça o primeiro encontro e o início das relações conflitantes entre o povo malinké e os franceses nas terras fictícias de Soba, a partir do olhar de um grande rei malinké, Djigui Keita, herdeiro da dinastia dos Keita. Em plena dominação colonial, Djigui Keita, no intuito de salvaguardar a sua dignidade e a sua soberania tradicional, não demora a empreender uma colaboração duvidosa com os colonos, em consequência de um mal-entendido voluntário do tradutor/interprete, Soumaré. De acordo com Gauvin (1997), a função de mediação da personagem tradutor/intérprete (Soumaré) permitiu ao escritor marfinense exibir a complexidade e a ambiguidade dos diálogos das culturas e das civilizações.

0 problema que se coloca, na verdade, para o romancista, é que essas personagens são colocadas em uma situação em que a língua africana e a língua ocidental entrem em choque. 0 conflito de visões é refletido também pela divergência de 
línguas. Nesta situação, o intérprete aparece no decorrer da narrativa como o símbolo do bilinguismo e do conciliador de duas percepções de uma realidade complexa. Como sabido, as obras de Kourouma foram alvo de inúmeras leituras críticas que, de certa forma, apontam características muito reducionistas, pois, tendem descartar quaisquer aspectos do romance que não se enquadrem nos padrões textuais eurocêntricos. De acordo com Koné,

Kourouma propõe em seus livros uma dimensão que recebeu menos atenção da sua crítica. Pois, de fato, o interesse da língua reside não apenas em sua originalidade sintática e léxica, mas também em sua capacidade de traduzir a realidade de forma satisfatória. Em outras palavras, se a língua usada por Kourouma for considerada muito eficaz, é porque traduz melhor do que outros a realidade vivida, ou seja, o biculturalismo em que vive o africano desde o período colonial até os dias de hoje (1995, p. 12-13). ${ }^{2}$

${ }^{2}$ Kourouma propose dans ses livres, une dimension qui a moins retenu l'attention de la critique. Car, en fait, l'intérêt de la langue se situe non seulement dans son originalité syntaxique et lexicale mais aussi dans sa capacité de traduire la réalité de façon satisfaisante. Autrement dit, si la langue utilisée par Kourouma est considérée comme très efficace, c'est qu'elle arrive mieux que d'autres à traduire la réalité vécue, c'est-à-dire le biculturalisme que vit l'africain depuis la période coloniale jusqu'à nos jours. (Koné, 1995, p.12-13) 
Publicados na Franca, os seus romances trazem à tona várias inovações tanto temáticas como estilísticas. Ao analisar, principalmente, Monnè, outrage et défis, vários estudos testemunham uma transformação gradual na sua escrita, especificamente, no plano da linguagem. Assim, deparamo-nos, dentre outros aspectos, com a complexidade da escrita como representação da realidade, com um importante sincretismo e hibridização do francês com o malinké, que Ana Mafalda Leite (2010, p. 157) define como um "fenômeno pelo qual os elementos linguístico-culturais, previamente distintos se misturam numa resultante única”. Kourouma, portanto, utiliza a forma romanesca para se contrapor às regras estabelecidas pela metrópole.

0 romancista recorre ao poder da linguagem e acredita profundamente na sua função crucial como instrumento de poder e de dominação. Assim, desde a publicação do seu primeiro livro, Les soleils des indépendances (1968), ele que nunca teve uma formação literária, inventa uma nova forma de se expressar. Como enfatiza Borgomano (1998), não se trata de reproduzir os diversos idiomas falados em África, mas trata-se de criar, a partir de uma influência formal estrangeira, uma nova linguagem, fictícia, híbrida e significativa capaz de expressar e representar a realidade em que vivem suas personagens. A partir dessa linguagem nova, construída pelo romancista, a sua 
escrita enriqueceu-se e seu projeto artístico e literário desenvolveram-se na subversão da língua francesa, escapando assim de um sistema de dominação.

Em Monnè, Outrage et Défis (1990), como parte das estratégias linguísticas, destacamos a presença de ritmos inspirados em epopeias africanas que articulam habilmente o discurso embebido de provérbios, às vezes, não traduzidos e que se revelam, na sua maioria, muito difícil de entender para o leitor não malinké. Ao referirmo-nos a seguinte fala do autor, é possível alegar estarmos diante de um processo de africanização do romance.

O que eu fiz? Simplesmente deixei fluir o meu temperamento distorcendo uma língua clássica muito rígida para que os meus pensamentos se movam nela. Então, eu traduzi o malinké para o francês, quebrando o francês para encontrar e restaurar o ritmo africano (KOUROUMA, 1997, p.116). ${ }^{3}$

O escritor marfinense não se limita a um exotismo ao introduzir algumas palavras de origens africanas na sua narrativa - lembrando que o autor, afinal, não é um francês, mas simplesmente ousou escrever o

\footnotetext{
${ }^{3}$ Qu'avais-je donc fait? Simplement donné libre cours à mon tempérament em distordantune langue classique trop rigide pour que ma pensées'y meuve. J'ai donc traduit le malinké en français em cassant le français pour trouver et restituer le rythme africain" (KOUROUMA, 1997, p.116).
} 
malinké em francês. Quando percorremos o romance, deparamo-nos com um discurso autêntico africano, com vozes africanas, pois, o autor recusa a inadequação entre sentimentos e expressão. 0 escritor, ao remodelar a língua francesa às estruturas linguísticas malinkés, desafia e desestabiliza as convenções e, como alega Ana Mafalda Leite, "recusa a posição privilegiada de um código padrão de uma língua, bem como de qualquer aspecto monocêntrico da experiência humana" (2010, p. 157). É sobre essa relação da língua e da literatura que Casanova discorre no seu livro, $A$ república mundial das letras, ao enfatizar que

A questão da literatura é evidente e diretamente ligada, embora por laços muito complexos, à da língua. 0 escritor mantém com sua língua literária (que nem sempre é sua língua materna, nem sua língua nacional) relações diretamente singulares e íntimas. [...]. Dela faz-se um uso claramente político - e ela é ao mesmo tempo a "matéria-prima" específica dos escritores [...] que aos poucos criam as condições de sua liberdade literária por meio da invenção de línguas especificamente literárias (2002, p. 65-66).

A alegação da estudiosa alavanca reflexões sobre a luta pela identidade e pela legitimação das literaturas africanas no universo literário mundial. Sem dú- 
vida, isso nos leva a pensar no texto Conjeturas sobre a literatura mundial (2000), em que Franco Moretti explora a relação do romance moderno dentro de um sistema mundial de literaturas inter-relacionadas. Segundo Moretti (2000, p. 178), a literatura mundial é um sistema de variações, isto é, todas as literaturas inter-relacionam-se, mas sofrem a pressão do centro para que tornem uniforme, porém, jamais conseguiria apagar de vez as realidades da diferença. Para o crítico, é isso que torna a literatura "una e desigual", portanto, "o estudo da literatura mundial é uma luta pela hegemonia simbólica ao redor do mundo" (2000, p. 178). No entanto, Moretti sugere uma transformação da literatura mundial de um ideal a um método que ele chama de reading distant (literatura a distância) que poderá dar conta das complexidades dos estudos da literatura produzida no mundo. Trata-se, nesse caso, de olhar em perspectiva, de forma a distinguir os caminhos e tendências que o romance está tomando.

Assim, Moretti alerta para a necessidade de uma descentralização da visão da literatura centrada no mundo euro-norte-americano e olhar para as especificidades das literaturas periféricas. Analisar o que estas literaturas centro/periferia têm em comum e de diferente, essencialmente, na evolução das formas no espaço e no tempo, tendo em vista que "os gêne- 
ros literários não sobreviveriam sem a variação cultural" sem essas interferências assimétricas (2000, p. 178). Ainda segundo o crítico, citando Max e Engels: "a unilateralidade e a obtusidade ficam cada vez mais improváveis, e das muitas literaturas nacionais e locais emerge uma literatura mundial" (2000, p. 173). Cabe alegar que a literatura mundial se compõe de um conjunto de práticas e valores que transcendem as fronteiras nacionais. Dessa forma, o crítico sugere um estudo da evolução da forma nas diferentes culturas do mundo como uma possível solução para o estudo da literatura.

Partindo da "lei de evolução literária" cunhado por Fredric Jameson, Moretti adverte para o fato de que em "culturas que integram a periferia do sistema literário [...] o romance moderno desponta não como um desenvolvimento autônomo, mas como uma conciliação entre uma influência formal ocidental (em geral francesa ou inglesa) e matérias locais" (2000, p. 177). Para além de uma mera conciliação entre a forma estrangeira e os conteúdos locais, Moretti refere-se, sobretudo, a uma combinação da forma estrangeira com matérias locais constituídos por personagens e vozes narrativas que defendem e veiculam os sentimentos localistas. Em Monnè, outrage et défis (1990), o tratamento dado às línguas locais e ao francês evidencia de certa forma esta dialética entre 
modelo estrangeiro e realidades locais. Com efeito, a primeira constatação que fizemos ao debruçarmo-nos sobre o romance é a intrusão de uma série de neologismos que permeiam toda a narrativa, além de uma grande quantidade de vocábulos em língua malinké, principalmente, e de outras línguas, como o árabe, o inglês e o uolof.

Esse repertório lexical é usado através de duas formas discursivas. A primeira, por meio do discurso direto: do francês para o malinké; e a segunda, através do discurso indireto do francês para outras línguas, como o uolof e o árabe, com as palavras e expressões como Allahou Akbar, bissimilaï, Al Imam, allah, Al fatiha, almamy, que são respectivamente uma deformação fonética e morfológica dos vocábulos árabes: Al fatiha, nome que designa a abertura da primeira surate (versículo) do Alcorão; Allahou Akbar, que significa Deus é poderoso; Al Imam, guia religioso. Esse mesmo neologismo aparece também nas línguas africanas, como o uolof, entre as quais podemos citar toubab para designar o homem branco ou homem civilizado. Tabaski ou Aïd el Ada em árabo-berbere, que literalmente significa o sacrifício religioso do carneiro para os muçulmanos, lembrando os contatos históricos dos povos malinkés com os berberes nos séculos VIII e XV atrelados aos fenómenos de migrações ocorridos dentro do continente que, de certa 
forma, contribuíram também para a criação de novos vocábulos. Assim, as palavras de origem francesa, como progrissi, para dizer progressista, allamas, para designar os alemães, pratati, para falar de prestação, ou nazaras, para designar os nazarenos ou missionários brancos, misérer, para se referir a palavra miséria. Assim, podemos dizer que por não encontrar, às vezes, palavras correspondentes em malinké os colonizados desenvolvem neologismos ou criam as próprias expressões para se comunicar, como aparece no seguinte relato do narrador:

0 intérprete explica por que a pratati [prestação] do griot não era nada. Elas não lucravam. Não eram o grande desígnio da colonização; esse desígnio chamava-se a civilização que por falta de palavra correspondente, ele [o intérprete] traduziu se «tornar toubab» [tornar-se um branco] (KOUROUMA, 1990, p. 57). ${ }^{4}$

Quanto ao discurso direto do léxico malinké, maioritariamente dominante, espalha-se no tecido ficcional do romance. Entre ele podemos citar: $n ' k o-$ ron, Bolloda, monnè, kébi, louboussi, déguè, sissa-sissa,

4"I'interprète explique pourquoi les pratati du griot n'etait rien. Elles ne faisaient pas gagner de l'argent. Elles n'étaient pas le grand dessein de la colonisation; ce dessein s'appelait la civilisation que, faute de mot correspondant, il traduisit par «devenir toubab»[um blanc]" (KOUROUMA, 1990, p.57). 
hérémakono, bilakoro, naikaisso, Djigui, Djéliba tanto para designar lugares quanto nomes de personagens ou de animais. Como já foi sublinhado, anteriormente, esse léxico seletivo ora é traduzido ora não. Importante salientar que o autor não procura dar aos seus leitores uma tradução fiel das palavras e expressões usadas, mas busca apenas adaptá-las ao sentido do texto, por meio de parênteses e quando necessário. Por exemplo, quando ele usa palavras como: Djigui, logo em seguida o sentido é colocado entre parênteses (Djigui significa em malinké o macho solitário, o ex-líder da banda de animais selvagens derrotados e expulsos da banda por um filhote jovem que se tornou mais forte) (p. 159), naikaisso (cavalo de ferro) para designar a bicicleta, instrumento até então desconhecido pelos moradores de soba (p. 224). Da mesma forma com a palavra louboussi (o cavalo do rei), bilakoro (homem não circunciso), Kébi (prédio administrativo) (p. 171) entre outras.

De acordo com Leite (2010, p. 158), a utilização de palavras ou expressões não traduzidas obriga o leitor a confrontar-se com uma outra cultura onde tais expressões têm significado. E, se houver tradução, manifesta-se uma particular interpretação, porque desenvolvem-se formas específicas e intencionais de construir distância cultural criada pela língua. Há ainda na obra a forte presença de descontinuidade, 
isto é, cenas justapostas, não seguindo uma sequência e muitas vezes nem mesmo o sentido da ligação entre as palavras é dado ao leitor.

Com efeito, o conjunto dessas técnicas lexicais podem interpretar um "ato político de afirmação da diferença” (LEITE, 2010, p. 158), uma forma de contestação da hegemonia ocidental. Frequente também o uso esporádico de palavras em itálico ou colocadas entre aspas, como soleils ou civilisation (p. 57), que enfatizam o neologismo pelo qual o francês intervém de uma forma ou outra no processo de comunicação. Também salientamos a presença de provérbios no início de cada capítulo e que de certa forma carrega todo o sentido do capítulo.

Herdados da tradição oral, os provérbios são uma manifestação poética popular em África. Segundo Pagnet (2017), eles nascem da experiência vivida pelos homens e traduzem uma verdade da experiência para ajustar um conselho ou para descrever um fato que se desdobra em torno de um imaginário que estabelece uma analogia com a realidade a ser expressa. Portanto, cabe argumentar que ao se servir dos provérbios nas suas narrativas, Kourouma nos apresenta as experiências e o diálogo com as formas africanas de se expressar e representar o mundo em que vivem as suas personagens. 
Sobressai a estética fragmentária, isto é, o uso acumulado de sinónimos para exprimir uma realidade, um sentimento, como revela o próprio título do romance, composto por uma sequência de três substantivos apostos: Monnè, outrages et défis - o primeiro malinké, os dois outros franceses. 0 narrador propõe, pelos dois substantivos franceses apostos, um ensaio sobre a tentativa de traduzir o termo monnè na língua do colonizador. Essa empreitada é evidenciada no primeiro encontro do Comandante francês e do rei Djigui, mediado pelo intérprete:

Um dia, o Centenário [Djigui] pergunta ao branco como ele entendia em francês a palavra monnè.

«Ultrajes, desafios, desprezo, insultos, humilhações, ira, todas essas palavras de uma vez sem que nenhuma a traduz realmente», respondeu o Toubab [Comandante] que acrescentou:

«Na verdade, não há para nós Europeus uma palavra, um equivalente absoluto ao monnè malinké».

Como na língua deles não tinha a palavra, o Centenário conclui que os franceses não conheciam o monnew. E a existência de um povo nazareno, que ainda por cima, não tinha vivido e não conhecia todos os ultrajes, desafios e desprezos os quais ele e seu povo 
sofriam tanto, aquilo permaneceu para ele [o Centenário], toda a vida, um maravilhamento, as origens e os motivos de graves meditações (KOUROUMA, 1990, p. 9). ${ }^{5}$

Ao dar destaque a essa epígrafe, o narrador reflete não apenas a gênese da relação entre colonizadores e colonizados, insistindo nas diferentes manipulações linguísticas que, desde os primeiros encontros, criaram as condições favoráveis ao estabelecimento de um novo sistema de opressão, mas também chama atenção dos leitores a respeito das dificuldades de escolha das palavras adequadas - dificuldades ligadas à incompatibilidade de certas expressões ou palavras malinkés ao francês. Diante desse obstáculo linguístico, o substantivo monnè nunca será traduzido. Todo esse processo, portanto, confirma a dialética entre a forma estrangeira e local apontada por Moretti, da qual os escritores africanos não têm como

\footnotetext{
${ }^{5}$ Un jour, le Centenaire [Djigui] demande au Blanc comment s'entend en français le mot monnè. «Outrages, défis, mépris, injures, humiliations, colère rageuse, tous ces mots à la fois sans qu'aucun le traduise véritablement» répond le Toubab [Comandant] qui ajouta: «En vérité, il n'y a pas chez nous les Européens une parole rendant totalement le monnè malinké». Parce que leur langue ne possédait pas le mot, le Centenaire en conclut que les Français ne connaissaient pas les monnew. Et l'existence d'un peuple, nazaréen de surcroît, qui n'avait pas vécu et ne connaissait pas tous les outrages, défis et mépris dont lui et son peuple pâtissaient tant, resta pour lui, toute la vie, un émerveillement, les sources et les motifs de graves méditations (KOUROUMA, 1990, p. 9).
} 
fugir. A criação desses efeitos reais e sutis nos parece ser a inovação mais importante de Kourouma para o romance africano. Portanto, é possível alegar que a originalidade dos seus romances reside na forma como ele manipula a linguagem e, conforme argumenta Koné (1995), a africanização da língua francesa não é uma mera técnica retórica nem uma busca artificial por efeitos estilísticos, mas obedece a uma necessidade de representar a complexidade da realidade africana que é diferente, de acordo com as perspectivas sob a qual é vista. Com efeito, ao optar por essa forma romanesca de escrita Kourouma (1997) alega que escrever em francês e continuar a pensar na língua materna não constrói, apenas um lar materno ao escritor francófono, mas permite de realizar uma francofonia aberta, multicultural que pode reunir povos iguais que consideram o francês como um bem comum.

É evidente que em África a questão da língua literária está estritamente relacionada ao espaço em que esta literatura circula. É incontestável que a maior parte das obras são editadas nos espaços linguísticos que correspondem aos antigos impérios coloniais. Assim, a partir da visibilidade literária em torno do espaço geocultural e de questão de legitimação e de luta de reconhecimento dentro do espaço literário mundial advogada por Pascale Casanova, propomos, 
na próxima secção, discutir a forma como ocorre a luta pelo reconhecimento da literatura africana de expressão francesa, especialmente no circuito literário parisiense na década de 1970, quando foi publicado o primeiro romance de Kourouma.

\section{A busca por uma visibilidade no sistema literário mundial}

As desigualdades sociais entre as regiões mais avançadas do mundo e aquelas em "via de desenvolvimento" são fenômenos antigos. Em se tratar de países africanos decorrem do processo iniciado com a colonização e que vêm passando várias etapas entre as quais a mais recente: a "globalização". Embora exista quem considere importante o fenômeno da globalização no nivelamento e união das nações e na ampliação das possibilidades de trocas entre os países, tornando as fronteiras mais permeáveis, o que se tem notado, de fato, é o agravamento daquelas desigualdades com o surgimento de um sistema capitalista e a difusão de valores dominantes para toda a sociedade. Ao pensar a forma de operar do capitalismo internacional definido como "um sistema simultaneamente uno e desigual, com um centro e uma periferia vinculados num relacionamento de crescente desigualdade" (MORETTI, 2000, p. 173), não podemos deixar de fazer esses apontamentos que nos parecem 
alicerçar a escala de desenvolvimento econômico e social dessas nações, mas também determinar o desenvolvimento das suas literaturas.

A literatura aparece como um campo atravessado por aspectos sociais que impactam as formas estéticas, modificando uma visão do que é considerado cânone e o estilo de determinado escritor. Parte importante dessa transformação passa pela compreensão de que as noções de centro e de periferia são definidoras do fenômeno literário e estão associadas ao lugar mais ou menos hegemônico que os países ocupam na ordem mundial. Como enfatiza Pascale Casanova (2002), o mapa literário e intelectual não se confunde com o mapa político nem a história literária pode ser reduzida à história política. Porém, a existência do espaço literário nacional supõe o acesso da nação a uma verdadeira independência política. Isso significa que o espaço literário é relativamente atrelado às estruturas políticas do seu país, as dependências literárias internacionais estão relacionadas às estruturas de poder política e econômica internacional. Ainda segundo Casanova (2002), o patrimônio literário está intimamente relacionado às instâncias nacionais. Vistas dessa forma, as relações de força literária passam também por relações de força política e pelo controle da organização editorial. 
A produção literária dos escritores francófonos necessita passar por grandes centros, como Paris, para ser legitimada. Os autores africanos são pouco lidos nos seus países de origem e é nas metrópoles que eles encontram um público mais vasto que, como observa Inocência Mata, gera "uma reedição da política do assimilacionismo cultural e de continuidade do império na cultura" (2007, p. 288). Assim, a busca pela notoriedade internacional não está isenta de riscos para os escritores africanos.

No entanto, a criação literária, assim como os trabalhos de produção buscam entrar no quadro do circuito comercial em escala planetária. Essa nova realidade tem o corolário, os requisitos da editora que impõe sua política editorial. 0 escritor deve, às vezes, dobrar-se a uma série de constrangimentos que desnaturam sua criação literária. E isso é revelador das políticas editoriais e da circulação dentro de uma esfera de poder que entravam a entrada do que pode ser percebido como diferente. Nessa lógica, é fácil deduzir que os escritores de países do Terceiro-Mundo enfrentam uma luta de legitimação em seu país em busca de reconhecimento no espaço literário mundial que, de acordo com Casanova, é "[...] um local de lutas incessantes, de constatações da autoridade e da legitimidade, de rebeliões, de insubmissões e até de revoluções literárias que conseguem modificar 
as relações de força e provocar reviravoltas nas hierarquias" (2002, p. 217). Nessa lógica, podemos dizer que o maior entrave atualmente talvez seja a persistência das relações de poder entre literaturas dominantes e dominadas, determinadas por um sistema de hierarquias de línguas do mundo.

São essas mesmas relações de poderes que permeiam o universo literário das ex-colônias da França. Desde a segunda metade do século XX, Paris não é mais apenas o centro colonial de uma produção literária francesa que os escritores dos países colonizados procurariam imitar, mas ela ampliou seus limites, com a independência e a descolonização para se tornar o centro editorial da produção literária de língua francesa no espaço mundial. Paris, a "república mundial das letras", o espaço de publicação, de crítica literária, através da massificação e da homogeneização, impõe os seus critérios à periferia que, na maioria dos casos, tenta adequar-se. Como afirma Owono Zambo (2012), Paris a terra de edição do pensamento africano, controla e censura tudo que não lhe parece enquadrar-se nas normas por ele estabelecidas.

Reconhecer a influência de Paris sobre as diversas literaturas nacionais não é um ofício difícil. Casanova aposta de forma clara que esta cidade é tradicionalmente percebida pelo mundo inteiro como a capital do universo literário, dotada do maior prestígio li- 
terário do mundo. Paris é, ao mesmo tempo, capital intelectual, árbitro do bom gosto, o lugar fundador da democracia política; seria um lugar transnacional cujos únicos imperativos são os da arte e da literatura. A antiguidade de sua literatura faz com que seja um espaço autônomo, renomado por sua liberdade e muito rico. Diante dessas circunstâncias, as periferias, como as ex-colônias, só podem passar por uma certa dominação, uma falta de reconhecimento. Acompanhando as reflexões da Casanova, podemos inferir que o drama dos escritores africanos é assim traçado. Eles se situam entre o monopólio exterior e a continuidade da política de subserviência colonial. Isso significa que os escritores africanos continuam tornando-se linguística e culturalmente colonizados. Eles não têm autonomia e são meros sujeitos que servem aos interesses parisienses, da sua língua de prestígio e de revelação do mundo.

Devido à falta de meios de comunicação e de difusão, os escritores da África francófona são altamente dependentes da importação de obras literárias da França, o que justifica a constante inclinação a estratégias de subversão. Assim, assistimos à instauração de um sistema literário "neocolonial". Kourouma em seus escritos e confissões lembra muito bem do desconforto que ele sentiu na busca por editores dispostos a publicar o seu manuscrito, Les soleils des 
indépendances. Em meados da década de 1960, o manuscrito foi rejeitado por vários editores de Paris e, de acordo com Steemers (2012), essa recusa deveu-se a uma suposta lacuna estética intransponível entre o manuscrito e o conceito de romance publicável naquela época. 0 livro foi julgado de maneira nada convencional no que tange à linguagem empregada, ainda que a língua seja um dos "principais componentes do capital literário” (CASANOVA, 2002, p. 26).

De fato, o francês africanizado, mas sobretudo, a desmistificação das independências no romance foram provavelmente umas das razões pelas quais o manuscrito demorou tanto para ser editado. Finalmente, foram as Imprensas da Universidade de Montreal que concordaram lançar o livro em 1967. Depois que recebeu o Prêmio literário da Francité no Quebec, as edições do Seuil de Paris decidiram resgatar os direitos do romance e publicá-lo, em 1970, na coleção “Cadre Rouge”, tradicionalmente reservada a escritores de nacionalidade francesa. Portanto, não esquecer aqui que em sua trajetória editorial o romance sofreu várias alterações ideológicas para satisfazer o gosto de um público leitor ocidental. Lembrando que Paris, o centro legitimador, pode desnacionalizar ou literarizar os textos que lhe chegam de horizontes longínquos para declará-los de valor e válidos no conjunto do universo literário sob sua juris- 
dição. Esses jogos de poderes apenas vêm reforçar os pressupostos de Moretti (2000, p. 175), de que o destino de uma cultura da periferia é cortado e alterado por outra cultura do centro que a ignora completamente. De fato, os mecanismos de reconhecimento e circulação literária são complexos. Eles acontecem apenas à custa de muitas negociações sobre o status e a identidade de uma literatura - especialmente em ex-colônias - e também são feitas, muitas vezes, à custa de muitos sacrifícios e compromissos incessantes com os mercados literários em geral. Nesse sentido Owono Zambo formula uma análise interessante, citando Mongo Béti:

Nossas obras são entregues à ditadura exclusiva de críticos, [...], comentaristas, cronistas não africanos do mundo francófono. Mesmo que a boa-fé destes últimos permaneça total, como eles poderiam impedir de atrair as nossas obras, inconscientemente, nas direções obrigatórias, nos túneis, nos becos sem saída, nos desvios que a cultura francesa instalou em sua consciência e onde nos outros não podemos ser encurralados apenas para sermos distorcidos? (OWONO ZAMBO, 2012, p. 16). ${ }^{6}$

\footnotetext{
${ }^{6}$ Nos oeuvres sont livrées à la dictature exclusive des critiques, commentateurs, [...] non-africains de la francophonie. Même si la bonne foi de ces derniers reste totale, comment pourraient-ils s'empêcher d'attirer nos oeuvres, inconsciemment, dans les sens obligatoires, les tunnels, les impasses, les voies de garage que la culture française a installés dans leur conscience et où nous autres nous ne pouvons être acculés que pour y être dénaturés? (OWONO ZAMBO, 2012, p. 16).
} 
A aparente despreocupação com a língua culta, associada à ruptura nos códigos literários da época, fez com que o romancista marfinense tivesse muitas vezes dificuldades em encontrar o seu lugar nos espaços literários franceses e mundiais. A reflexão a respeito da língua nacional e da linguagem literária configuram ainda, em suas obras, uma reflexão maior a respeito do papel do escritor. Kourouma articula essa angústia quando descreve os obstáculos que encontra na sua empreitada de romancista: "Meu primeiro problema como escritor, escritor francófono é antes de tudo uma questão de cultura... eu luto numa grande confusão de termos com expressões francesas que eu utilizo" (1997, p. 115). Contudo, a ideia de dominação contra a de liberdade criativa, a tensão entre uma concepção nacional e outra universal da literatura, impedem o escritor de desenvolver com segurança os argumentos de defesa do seu ponto de vista. No plano da escrita, Owono Zambo (2012, p. 14) argumenta que o francês faz do escritor africano um autor aprisionado num espaço linguístico que o confina numa espécie de melancolia da sua verdadeira vocação de contador. Os escritores africanos veem a língua francesa como uma realidade pós-colonial que eles não podem evitar, mas preferem usá-la engenhosamente para escrever de volta ao centro imperial. Assim, como argumenta Casanova, a obra de uma nação periférica pode não se aproximar da moderni- 
dade concebida por Paris, mas modificar as relações de forças e provocar reviravoltas nas hierarquias. É precisamente o que fez Kourouma no seu percurso literário ao utilizar elementos locais para romper a hegemonia da língua francesa.

Como escritor em busca de reconhecimento, o autor aceita, nas primeiras instâncias, submeter-se às leis impostas pelos editores para as expectativas literárias e editorais do "meridiano de Greenwich" e uma vez investido com o selo da legitimação e de visibilidade oferecido pela autoridade literária e editorial parisiense, ele explora sua escrita de forma mais livre numa tentativa não apenas de se libertar, mas também de reivindicar o seu pertencimento a uma produção literária mundial. Com efeito, se em seus dois primeiros romances, o autor interessou-se pelas questões linguísticas, observamos nas suas produções a seguir uma verdadeira busca poética que visa inscrever a sua produção fora do tempo e do espaço. 0 escritor marfinense parece ter ganhado em retrospecto e lucidez pelo menos o duplo caráter de sua audiência. Como essa consciência aparentemente mais aguda dos problemas colocados pelo destino de sua escrita se traduz em seu último romance, Allah n'est pas obligé (2000). 


\section{Referências}

CASANOVA, Pascale. A república mundial das letras. Tradução de Marina Appenzeller. São Paulo: Estação Liberdade, 2002.

BORGOMANO, Madeleine. Ahmadou Kourouma, le guerrier griot. Paris: L'harmattan, 1998.

GAUVIN, Lise. L'Écrivain francophone à la croisée des langues. Paris: Karthala, 1997.

KONÉ, Amadou. "L'effet de réel dans les romans de Kourouma”. Études françaises, vol. 31, no 1, p. 13-22. KOUROUMA, Ahmadou. "Écrire en français, penser dans sa langue maternelle". Etudes Françaises, vol. 33.1, 1997, p. 115-118.

KOUROUMA, Ahmadou. Monnè, outrage et défis. Paris: Le Seuil, 1990.

LEITE, Ana Mafalda. Representação da oralidade em textos literários africanos: heterolinguísmo e hibridismo de gêneros. In: SECCO, Carmen L. T.; SALGADO, Ma T.; JORGE, S. R. (orgs.). Pensando África: literatura, arte, cultura e ensino. Rio de Janeiro: Fundação Biblioteca Nacional, 2010. p. 157-164.

MATA, Inocência. A literatura africana e a crítica pós-colonial: reconversões. Luanda: Editorial Nzila, 2007. MORETTI, Franco. Conjecturas sobre a literatura mundial. Tradução de José Marcos Macedo. Novos Estudos. CEBRAP, n 58, novembro 2000 p. 173-181. 
OWONO ZAMBO, Claude Éric. Les contextes sociopolitiques d'une littérature au statut singulier. In: AMOUGOU, Louis Bertin (org.). Ce que Paris fait aux littératures francophones. La Tortue Verte revue en ligne des Littérature Francophone. Dossier no 1, 2012.

PAGNET, Clément. Le proverbe, un discours poétique au centre du système éducatif en Afrique traditionnelle. Norsud, no 9, jun, 2017.

STEEMERS, Vivan. The effect of translating "Big Words": anglophone translation and reception of Ahmadou Kourouma's Novel Allah n'est pas obligé. Research in African literatures, vol. 43, no 3 p. 36-53, 2012. Disponível em:<https://muse.jhu.edu/article/483365/pdf>. Acessado no dia 12 de junho 2019. 